\title{
Benchmarking Physiotherapists' Usual Care for Total Hip and Knee Joint Arthroplasty in Australia and New Zealand
}

Jessie Hart BPhysio, GradCertMuscPhysio

Senior Physiotherapist, Alfred Health, Melbourne, Australia

Kathryn Tarrant BHSC, MPhysioPrac

Senior Physiotherapist, St Vincent's Hospital, Melbourne, Australia

Susan Liew MBBS, FRACS

Director of Orthopaedics, Alfred Health, Melbourne, Australia

Lara Kimmel PhD, GradDipClinEpi, BPhysio

Allied Health Team Leader, Alfred Health, Melbourne, Australia

\section{ABSTRACT}

This study presents findings from a benchmarking survey describing reported practice in Australia and New Zealand for pre- and post-operative total joint arthroplasty management. The aim of this study was to identify differences in service delivery between both public and private healthcare sectors and geographical regions. Surveys were sent to senior physiotherapists and undertaken online. Responses were received from 125 institutions. Predicted length of stay (LOS) varied across regions with most therapists reporting an agreed LOS of $\geq 3$ days ( $83 \%$ total hip arthroplasty; $89 \%$ total knee arthroplasty). Significantly longer LOS was reported in the private healthcare sector $(p=0.001)$. Patients in New Zealand and Western Australia were reported as more likely to be discharged directly home following total hip arthroplasty $(p=0.001)$ and total knee arthroplasty $(p<0.001)$ compared with other regions. The majority of physiotherapists suggested they would mobilise patients on post-operative day 0 (total hip arthroplasty $53 \%$; total knee arthroplasty 55\%), with both hospital and patient factors cited as barriers to early mobility. Heterogeneity of care across both healthcare sector and region is prevalent following elective total joint arthroplasty in Australia and New Zealand. Research opportunities regarding optimal management remain, particularly in regard to discharge destination, length of stay, and timing of first mobility.

Hart, J., Tarrant, K., Liew, S., \& Kimmel, L. (2021). Benchmarking physiotherapists' usual care for total hip and knee joint arthroplasty in Australia and New Zealand. New Zealand Journal of Physiotherapy, 49(3), 99-111. https://doi. org/10.15619/NZJP/49.2.06

Key Words: Arthroplasty, Australia, Benchmarking, New Zealand, Physiotherapy

\section{INTRODUCTION}

Total joint arthroplasty (TJA) has been shown to improve function, pain, and quality of life for people living with severe joint disease such as osteoarthritis who have failed conservative management (Churches et al., 2019). In New Zealand in 2018, 9,186 primary total hip arthroplasties (THA) and 8,392 primary total knee arthroplasties (TKA) were performed across both the private and public healthcare sectors (The New Zealand Joint Registry, 2019). In the same year across Australia, 39,005 primary THA and 56,147 primary TKA were completed (Australian Orthopaedic Association National Joint Replacement Registry, 2018). In 2012/13, the cost of TJA to the Australian healthcare system was over $\$ 2.3$ billion (Australian Commission on Safety and Quality in Health Care, 2014). Given that conservative projections suggest that by 2046, Australia could be completing 94,086 THAs and 105,971 TKAs (Inacio et al., 2017), it is important to reduce unwarranted variation in rehabilitation and optimise management from both a health-related quality of life and health economic perspective (Australian Commission on Safety and Quality in Health Care, 2014; Australian Institute of Health and Welfare, 2019b). Similarly, in New Zealand, it is predicted that the absolute number of TJA will increase with a projected increase of THA by $84 \%$ and TKA by $183 \%$ from 2001 to 2026 (Hooper et al., 2014).

Heterogeneity in management of individuals following TJA has been reported across multiple domains. The Royal Australasian College of Surgeons (2018) suggested clinical variation following TJA may be a sign of system inefficiencies and therefore opportunity for improvement. Physiotherapy plays an essential role in the perioperative care of patients undergoing TJAs; however, variations in practice have been described in the acute and sub-acute settings (Artz et al., 2013; Jones et al., 2016). In a cohort of privately funded patients in Australia, patient-related factors explained only $24.6 \%$ of the variance in inpatient rehabilitation rates post-TKA with surgeon- or hospitalrelated factors comprising the remaining $75.4 \%$ (Schilling et al., 2018).

It is important that a benchmarking study includes both public and private hospitals to determine if patients are managed differently across these organisations. In both Australia and New Zealand, surgeons can work in private or public institutions (or both) and, as such, variation in management across these 
jurisdictions is of interest (Derrett et al., 2009). In Australia and New Zealand, all patients can receive access to TJA in the public system (Australian Government Services Australia, 2020; Lao et al., 2019). Private insurance funds most TJA in Australia (TKA 70.7\% and THA 59.9\% in 2019) (Australian Orthopaedic Association National Joint Replacement Registry, 2020), while in New Zealand most TJA are publicly funded (TKA 59\% and THA 54\% between 2005 and 2016), with others receiving TJA through private insurance and the Accident Compensation Corporation (Lao et al., 2019). Inpatient rehabilitation is offered by most private insurance companies in Australia, although for a pre-determined limited period of time (Naylor et al., 2019), whereas in New Zealand, follow-up rehabilitation care is described as occurring in the outpatient setting (Snell et al., 2020).

The primary purpose of this benchmarking survey was to describe reported current practice in Australia and New Zealand following TJA, especially in pre- and post-operative management. Additionally, we aimed to identify any differences in service delivery between the public and private healthcare sector or between regions in Australia and New Zealand and highlight potential areas for improvement.

\section{METHODS}

This online benchmarking survey was designed to inform current usual care in the pre-operative and early post-operative phase after elective primary TJA in Australia and New Zealand and to identify any variations in practice between regions or between private and public hospital systems.

Study data were collected and managed using REDCap (Research Electronic Data Capture) electronic data capture tools hosted at the Alfred Hospital, Melbourne (Harris et al., 2009; Harris et al., 2019).

As no validated tool existed for benchmarking management following TJA, a survey was designed using both open- and closed-ended questions. Questions were informed by previous surveys completed documenting physiotherapy management of individuals following TJA (Jones et al., 2016; Naylor et al., 2006). The survey questions were reviewed and piloted by a group of senior physiotherapists and researchers. Based on their feedback, the survey was modified and finalised (available upon request from authors). Questions addressed TKA and THA individually and were grouped into pre-operative management, early post-operative management, and discharge planning/ follow up.

The Australian and New Zealand Orthopaedic Associations' Joint Registry 2018 reports were used to identify hospitals which performed TJA (Australian Orthopaedic Association National Joint Replacement Registry, 2018; The New Zealand Joint Registry, 2019). Physiotherapy managers at each site were contacted via phone or email with a request for the contact email of the most senior physiotherapist responsible for the care of individuals following TJA. In cases where there was no physiotherapy department at a hospital site, the relevant contracted private physiotherapy practice was contacted where possible. The survey was then distributed via REDCap to the relevant physiotherapist between 28 November 2019 and 14
January 2020. Up to two reminders were sent by email through REDCap to non-responders two to four weeks after initial distribution to maximise response rates.

Those included in the study were allied health managers or physiotherapists who worked in hospitals listed in the 2018 Australian or New Zealand Joint Registry report. Exclusion criteria encompassed:

- hospital no longer completing TJA as at June 2019

- hospital closure

- hospital not routinely completing primary TJA in adults (children's hospital, oncology hospital, trauma hospital)

- no physiotherapy department or no primary physiotherapist responsible for overseeing the management of individuals following TJA at a hospital site

- requests for modification to approved ethics application following survey distribution

Ethics approval was granted by the Alfred Hospital Ethics Committee (project number 365/19).

Participants were provided with information in an email from REDCaps that included a link to access the survey. Participants indicated consent to participate by completion of the survey; therefore, any incomplete responses were not included in the analysis. The data were sub-grouped for analysis, comparing both public and private healthcare settings, and regions/states. Given the small number of hospitals in the Northern Territory, Australian Capital Territory, and Tasmania, their data were pooled together to maintain anonymity. New Zealand was treated as one region equivalent to a state. Where hospitals provided a length of stay (LOS) range (e.g., 3-5 days), the mean was used for the purpose of data analysis.

\section{Statistical analyses}

Data were divided into private and public hospital information and into states/regions for comparisons. Chi-squared or Fisher's exact tests (if cells contained fewer than five cases) were used for categorical data. Mann Whitney U or Kruskal Wallis tests were used to compare continuous data for groups that were non-parametric (Gaddis \& Gaddis, 1990). Data were analysed using Stata 14.0 (StataCorp, 2015). A $p$ value $<0.05$ was deemed to be significant.

\section{RESULTS}

The analyses included 125 responses, which accounted for $72.7 \%$ of all surveys sent to senior physiotherapists (Figure 1). Of the hospitals reported on, 44 were private, with 81 undertaking publicly funded TJA. All the hospitals reported undertaking both THA and TKA.

Differences in both hospital- and patient-related factors were reported between public and private hospital settings (Tables 1 and 2) and between regions (Tables 3 and 4). Regional differences in agreed mean LOS for THA and TKA were evident, reported as 3.5 days for TKA and 3.2 days for THA. Physiotherapists in New Zealand were more likely to report an agreed LOS of 3 days or less for both THA $(p=0.011)$ and TKA $(p=0.029)$. There was a significant difference between 


\section{Figure 1}

Flow Diagram of Completion and Response Rates

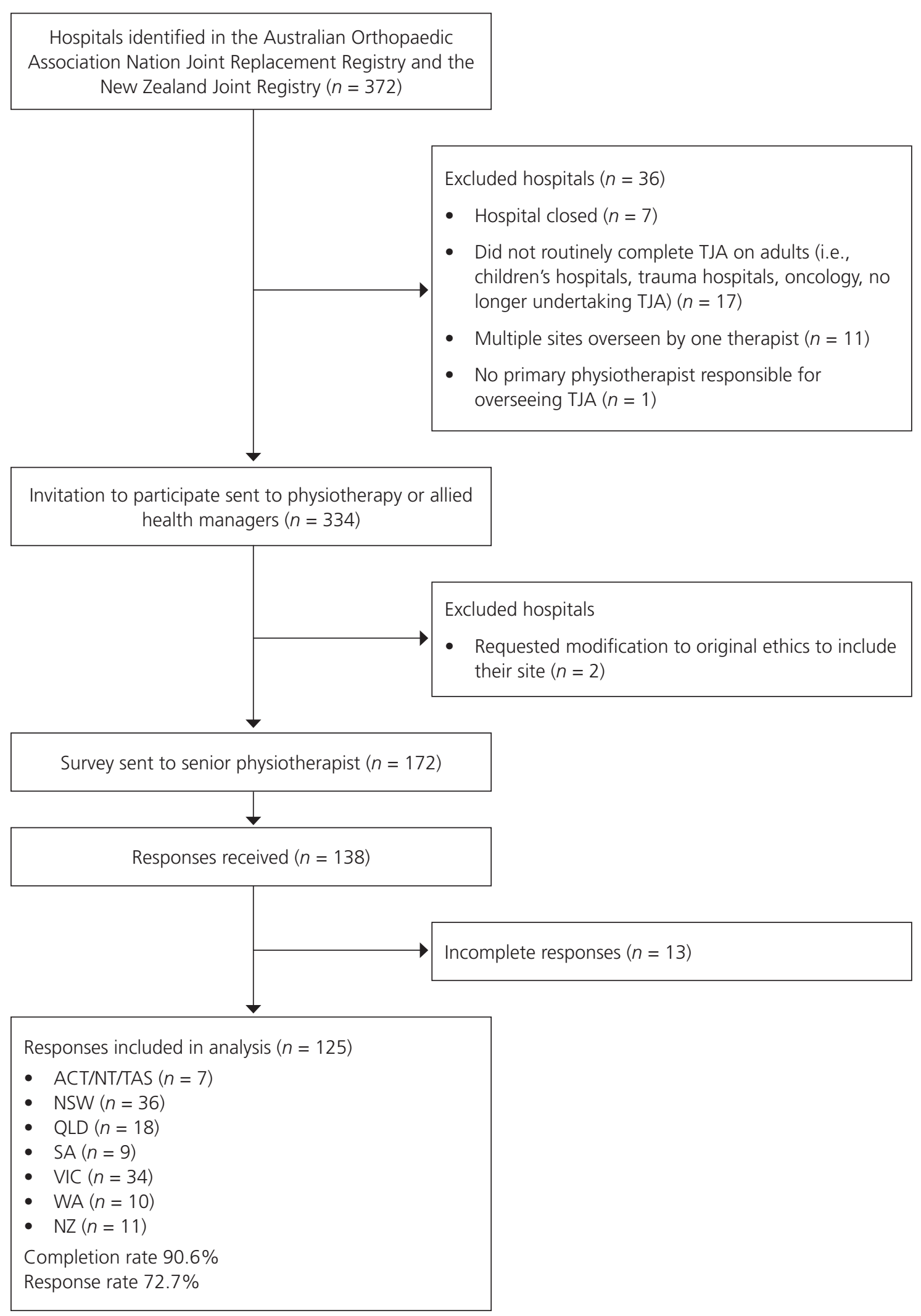

Note. ACT = Australian Capital Territory; NSW = New South Wales; NZ = New Zealand; NT = Northern Territory; QLD = Queensland; SA = South Australia; TAS = Tasmania; TJA = total joint arthroplasty; VIC = Victoria; WA = Western Australia. 
regions in terms of discharge destination following both TKA $(p<0.001)$ and THA $(p=0.001)$. Overall, the proportion of individuals discharged directly home was $>75 \%$ at $70.4 \%$ of sites following THA and $65.6 \%$ following TKA (Table 4; see Appendices $A$ and $B$ for details on discharge criteria). The most common perceived barriers to early mobility on post-operative day 0 (POD0) were both hospital/staffing-related factors and medical status or anaesthetic choice (Table 5). Physiotherapists were more likely to report a range of movement goal for TKA prior to discharge in the public system (Appendix $C, p=0.049$ ).

\section{DISCUSSION}

This is the largest benchmarking study completed examining usual care of individuals undergoing TJA in Australia and New Zealand from preadmission through to post-operative care. Across this jurisdiction, more TJAs are performed in private than public institutions, which was reflected in our response rate (Australian Commission on Safety and Quality in Health Care, 2014). The main finding of this benchmarking survey was a difference in the management of patients in the public and private sectors, with private institutions reporting a longer

\section{Table 1}

Demographic and Hospital Factors in Private and Public Hospitals ( $N=125)$

\begin{tabular}{lccccccc}
\hline \multirow{2}{*}{ Descriptor } & \multicolumn{2}{c}{ Total } & \multicolumn{2}{c}{ Private hospital } & \multicolumn{2}{c}{ Public hospital } \\
\cline { 2 - 6 } & Mdn & IQR & Mdn & IQR & Mdn & IQR & \multicolumn{1}{c}{$p$} \\
\hline THA per annum & 143 & $73-227$ & 200 & $90-325$ & 100 & $67-200$ & $<0.001$ \\
TKA per annum & 150 & $88-300$ & 225 & $90-510$ & 125 & $81-215$ & $<0.001$ \\
\hline
\end{tabular}

Pre-operative education

Yes 98

No

98

27

Is LOS predicted prior to hospital admission?

Yes

No

\section{8}

47

Use of discharge predictor tool Yes

No

101

Physiotherapy hours, Monday to

Friday

Business hours only

Early/late service

106

19

Physiotherapy hours, Saturday and

Sunday

Reduced/priority

Business hours only

Early/late service

No service

Other

Use of clinical pathway for TJA

$$
\text { Yes }
$$

No

84.8

15.2

62.4

37.6

19.2

80.8

61
49
4
7

61

49

4

4

7

88

37

Agreed LOS for THA

$$
\begin{aligned}
& <3 \text { days } \\
& 3 \text { days } \\
& >3 \text { days }
\end{aligned}
$$

Agreed LOS for TKA

$<3$ days
3 days
$>3$ days

$n \quad \%$

$\% \quad n$

32

$$
72.3
$$

66

81.5

0.256

12

27.3

15

18.5

$\%$

$\%$

$p$ 
Table 2

Patient-related Factors in Private and Public Hospitals $(N=125)$

\begin{tabular}{|c|c|c|c|c|c|c|c|}
\hline \multirow{2}{*}{ Descriptor } & \multicolumn{2}{|c|}{ Total } & \multicolumn{2}{|c|}{ Private hospital } & \multicolumn{2}{|c|}{ Public hospital } & \multirow{2}{*}{$p$} \\
\hline & $n$ & $\%$ & $n$ & $\%$ & $n$ & $\%$ & \\
\hline \multirow{2}{*}{\multicolumn{8}{|c|}{$\begin{array}{l}\text { Physiotherapist would review } \\
\text { patient POD0 } \\
\text { THA }\end{array}$}} \\
\hline & & & & & & & \\
\hline Yes & 77 & 61.6 & 33 & 75.0 & 44 & 54.3 & \multirow[t]{2}{*}{0.023} \\
\hline No & 48 & 38.4 & 11 & 25.0 & 37 & 45.7 & \\
\hline \multicolumn{8}{|l|}{ TKA } \\
\hline Yes & 83 & 66.4 & 34 & 77.3 & 49 & 60.5 & \multirow[t]{2}{*}{0.058} \\
\hline No & 42 & 33.6 & 10 & 22.7 & 32 & 39.5 & \\
\hline \multirow{2}{*}{\multicolumn{8}{|c|}{$\begin{array}{l}\text { Physiotherapist would stand/ } \\
\text { ambulate patient on POD0 } \\
\text { THA }\end{array}$}} \\
\hline & & & & & & & \\
\hline Yes & 66 & 52.8 & 30 & 68.2 & 36 & 44.4 & \multirow[t]{2}{*}{0.011} \\
\hline No & 59 & 47.2 & 14 & 31.8 & 45 & 55.6 & \\
\hline \multicolumn{8}{|l|}{ TKA } \\
\hline Yes & 69 & 55.2 & 31 & 70.5 & 38 & 46.9 & \multirow[t]{2}{*}{0.011} \\
\hline No & 56 & 44.8 & 13 & 29.5 & 43 & 53.1 & \\
\hline \multicolumn{8}{|c|}{$\begin{array}{l}\text { Nursing staff mobilise patients prior } \\
\text { to physiotherapy review }\end{array}$} \\
\hline Yes & 15 & 12.0 & 9 & 20.5 & 6 & 7.4 & \multirow[t]{2}{*}{0.032} \\
\hline No & 110 & 88.0 & 35 & 79.5 & 75 & 92.6 & \\
\hline \multicolumn{8}{|c|}{ Number of physiotherapy } \\
\hline sessions dai & & & & & & & \\
\hline$<1$ & 1 & 0.8 & 1 & 2.3 & 0 & 0 & \multirow[t]{4}{*}{0.225} \\
\hline 1 & 64 & 51.2 & 19 & 43.2 & 45 & 55.6 & \\
\hline 2 & 59 & 47.2 & 24 & 54.5 & 35 & 43.2 & \\
\hline$>2$ & 1 & 0.8 & 0 & 0 & 1 & 1.2 & \\
\hline \multicolumn{8}{|c|}{$\begin{array}{l}\text { Routine THA precautions } \\
\text { (posterior approach) }\end{array}$} \\
\hline Yes & 110 & 88.0 & 39 & 88.6 & 71 & 87.7 & \multirow[t]{2}{*}{0.872} \\
\hline No & 15 & 12.0 & 5 & 11.4 & 10 & 12.3 & \\
\hline $\begin{array}{r}\text { Routine THA } \\
\text { (anterior ap }\end{array}$ & & & & & & & \\
\hline Yes & 55 & 44.0 & 23 & 52.3 & 32 & 39.5 & 0.430 \\
\hline No & 19 & 15.2 & 6 & 13.6 & 13 & 16.0 & \\
\hline $\mathrm{N} / \mathrm{A}$ & 51 & 40.8 & 15 & 34.1 & 36 & 44.4 & \\
\hline Routine occup & & & & & & & \\
\hline THA & & & & & & & \\
\hline Yes & 96 & 76.8 & 20 & 45.5 & 76 & 93.8 & $<0.001$ \\
\hline No & 29 & 23.2 & 24 & 54.5 & 5 & 6.2 & \\
\hline TKA & & & & & & & \\
\hline Yes & 85 & 68.0 & 14 & 31.8 & 71 & 87.7 & $<0.001$ \\
\hline No & 40 & 32.0 & 30 & 68.2 & 10 & 12.3 & \\
\hline $\begin{array}{r}\text { Percentage of } \\
\text { directly hom }\end{array}$ & & & & & & & \\
\hline THA & & & & & & & \\
\hline$<75 \%$ & 37 & 29.6 & 14 & 31.8 & 23 & 28.4 & 0.689 \\
\hline$\geq 75 \%$ & 88 & 70.4 & 30 & 68.2 & 58 & 71.6 & \\
\hline TKA & & & & & & & \\
\hline$<75 \%$ & 43 & 34.4 & 20 & 45.5 & 23 & 28.4 & 0.055 \\
\hline$\geq 75 \%$ & 82 & 65.6 & 24 & 54.5 & 58 & 71.6 & \\
\hline Routine follov & & & & & & & \\
\hline THA & & & & & & & \\
\hline Yes & 95 & 76.0 & 31 & 70.5 & 64 & 79 & 0.285 \\
\hline No & 30 & 24.0 & 13 & 29.5 & 17 & 21 & \\
\hline TKA & & & & & & & \\
\hline Yes & 117 & 93.6 & 39 & 88.6 & 78 & 96.3 & 0.128 \\
\hline No & 8 & 6.4 & 5 & 11.4 & 3 & 3.7 & \\
\hline
\end{tabular}

Note. $\mathrm{THA}=$ total hip arthroplasty; TKA = total knee arthroplasty; POD0 = post-operative day 0. 


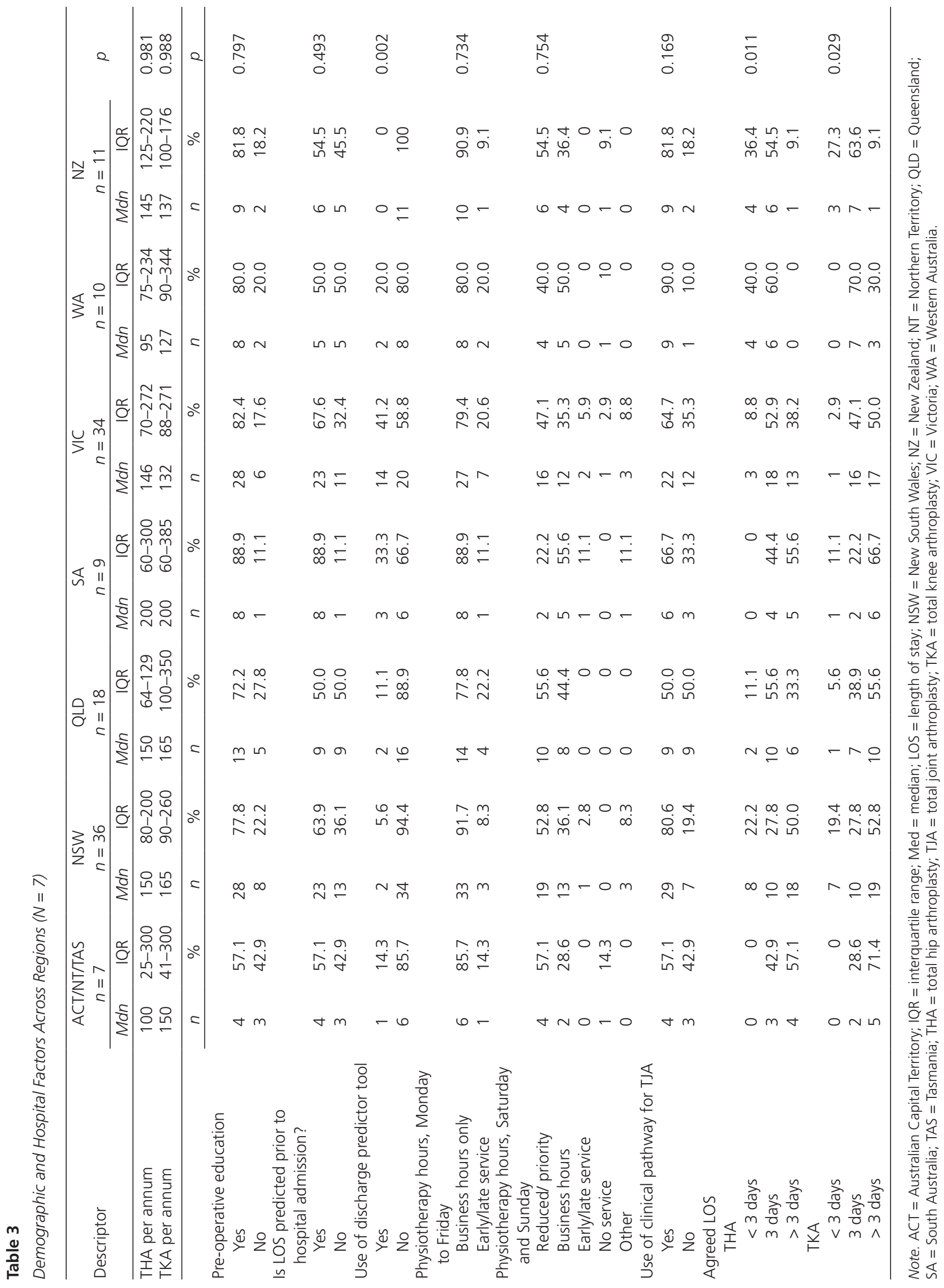




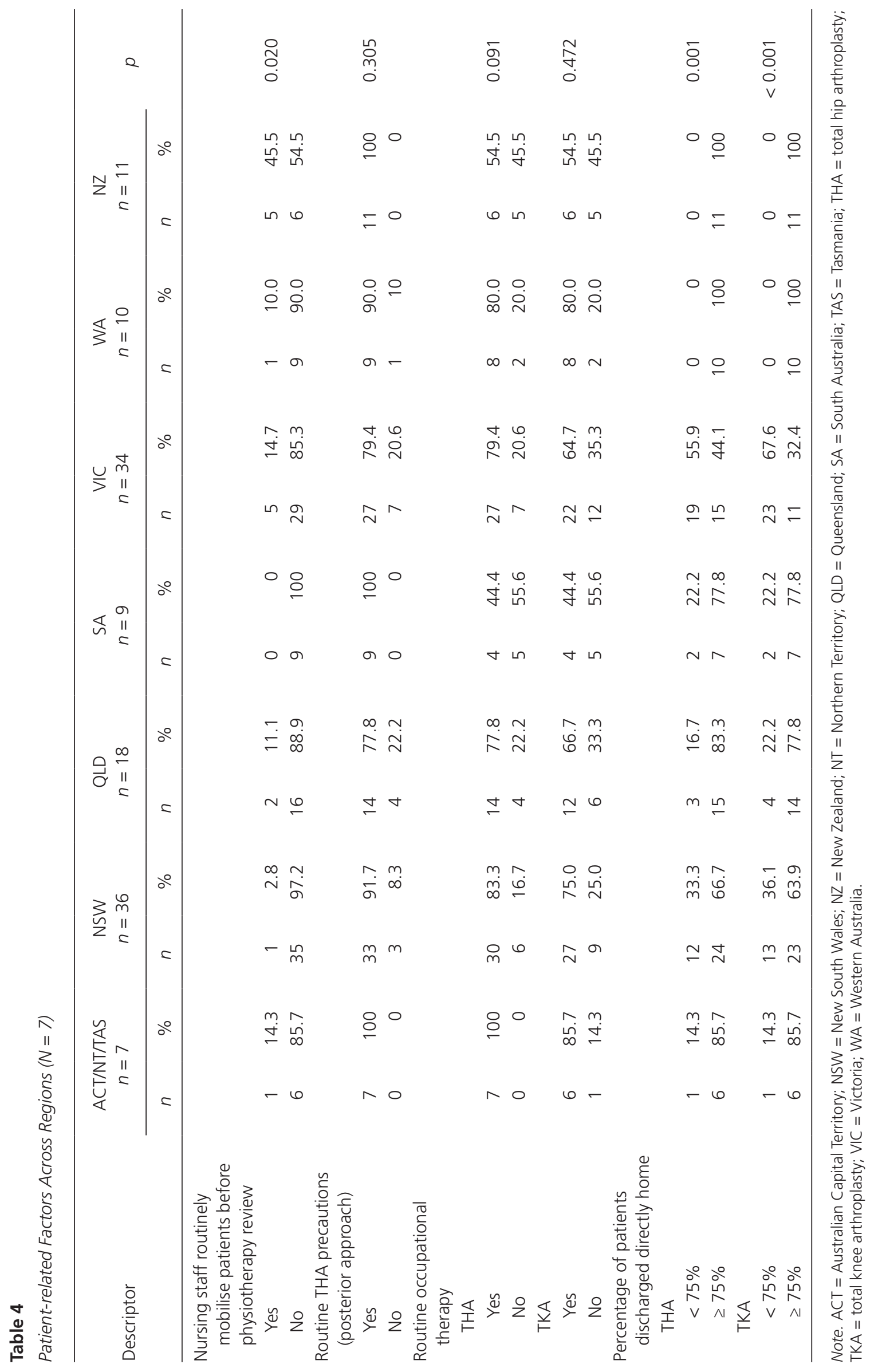




\section{Table 5}

Reported Barriers to Earlier Mobility

\begin{tabular}{lcc}
\hline Barriers & $n$ & $\%$ a \\
\hline Medical status including anaesthetic choice/use of nerve blocks & 67 & 53.6 \\
Staffing/resources (including late return to ward and no staff available) & 67 & 53.6 \\
Surgeon preference & 37 & 29.6 \\
Available evidence/local practice & 11 & 8.8 \\
No barriers to early mobility reported & 10 & 8.0 \\
Stairs are the only thing that would not be trialled on post-operative day 0 in the medically well patient & 7 \\
\hline
\end{tabular}

a Percentage $\neq 100$ as some sites reported multiple barriers to earlier mobility.

agreed LOS, increased access to mobilisation on PODO and a 7 rather than a 5-day service. Regional differences were also shown in agreed LOS and the percentage of patients discharged directly home as opposed to inpatient rehabilitation. Wide variations were found in post-operative management such as use of precautions and early mobilisation, and consideration should be given to the development of guidelines by an expert multidisciplinary team including surgeons, nursing, and allied health that could facilitate more standard care for patients regardless of funding models or jurisdiction.

Therapists in private hospitals reported a significantly longer agreed LOS for individuals following TKA than their public counterparts $(p=0.001)$, despite reports that privately funded patients have less comorbidities than those funded publicly (Naylor et al., 2019). LOS may be longer in private hospitals, as private health insurers provide inpatient rehabilitation funding for a pre-determined LOS (rather than as needed). A regional difference in agreed LOS was identified for both THA ( $p=$ $0.011)$ and TKA ( $p=0.029)$, with the shortest agreed LOS reported in New Zealand (mean THA $=2.8$ days, mean TKA = 2.8 days) and Western Australia (mean THA $=2.6$ days, mean TKA $=3.3$ days), and the longest reported in Australian Capital Territory/Northern Territory/Tasmania (mean THA 3.7 days, mean TKA = 3.9 days). The agreed LOS reported by therapists in New Zealand following THA and TKA is shorter than the median LOS of 4 days reported in these populations in 2017 (Proudfoot et al., 2017).

As health insurance status and surgeon affiliation, as well as patient-related factors, have been identified as potential predictors of discharge destination following THA (London et al., 2016; Schilling et al., 2018), use of a validated outcome tool to predict LOS may assist in decreasing unwarranted variation between health services. While the majority of respondents $(62.4 \%)$ reported predicting LOS prior to admission, only $30.8 \%$ of those reported use of a discharge prediction tool. These 24 sites all used the Risk Assessment and Prediction tool (RAPT), which has demonstrated utility in both decreasing LOS following TJA and identifying those who benefit from targeted intervention to reduce risk of delayed post-operative recovery (Sconza et al., 2019). Patients' expectations have been found to have an influence on discharge setting and LOS, and use of the RAPT can identify individuals who may benefit from pre-operative counselling and education (Sconza et al., 2019). Surgeons' recommendations and hospital factors also influence patient discharge disposition and this could be further investigated to reduce unwarranted variation in care (London et al., 2016; Schilling et al., 2018). Despite growing interest in 'outpatient' TJA (Meneghini et al., 2018), most therapists (83\% THA, 89\% TKA) reported an agreed LOS of 3 or more days and many still utilise inpatient rehabilitation. Significant changes would need to be undertaken in order to facilitate widespread uptake of outpatient TJA in this jurisdiction.

No significant difference in perceived numbers of individuals discharged directly home following TJA was reported by physiotherapists in public and private hospitals across Australia and New Zealand. A recent prospective study completed in Australia found privately funded patients were more likely to discharge to inpatient rehabilitation following both TKA and THA (Naylor et al., 2019). In Australia in 2017-2018, private hospitals provided $95 \%$ of rehabilitation episodes of care for gonarthrosis (arthrosis of the knee) and 94\% for coxarthrosis (arthrosis of the hip) (Australian Institute of Health and Welfare, 2019a). We suspect these admissions are for care post arthroplasty, although there may also be some admissions for other reasons to do with the patients' arthritic conditions.

When investigating regional differences, individuals in Victoria were reported to be significantly more likely to be discharged to inpatient rehabilitation following both THA $(p=0.001)$ and TKA $(p<0.001)$, despite Victoria having a small number of rehabilitation admissions per 1,000 population (Australian Institute of Health and Welfare, 2019a). These regional differences are important, despite no significant difference being found in our study between discharge destination from private and public hospitals ( $p=0.055$ ). The over-representation of Victorian hospitals in our data may influence this result as this state has an increased use of inpatient rehabilitation as a discharge destination following TJA for both public and private patients.

Weekend physiotherapy service was reported by physiotherapists as being provided by the majority of hospitals (96.8\%) in Australia and New Zealand for patients undergoing TJA. The provision of a weekend physiotherapy service has demonstrated increased functional mobility and a reduced need for inpatient rehabilitation following TJA (Haas et al., 2018). However, the 
effects of a weekend service on LOS vary in the literature (Haas et al., 2018; Pengas et al., 2015). Public hospitals were more likely to provide a reduced/priority weekend service (59.3\% vs $29.5 \%, p=0.01)$, whereas the private hospitals were more likely to provide a business hours service ( $59 \%$ vs $28.4 \%, p=0.001$ ). Although there is research to support weekend physiotherapy, further research around benefits and cost of different models of service is required.

Mobilisation on PODO following TJA has been suggested to reduce hospital LOS for some individuals without increasing adverse outcome (Gwynne-Jones et al., 2017; Tayrose et al., 2013). Despite this, only $53 \%$ and $55 \%$ of physiotherapists treating THA and TKA, respectively, suggest they would mobilise individuals on POD0. Private hospital physiotherapists suggested they were more likely to mobilise patients POD0 compared to public hospital physiotherapists (THA $68.2 \%$ vs $44.4 \%, p=$ 0.011 and TKA $70.5 \%$ vs $46.9 \%, p=0.011$ ); however, it is unknown how many actually routinely mobilise their patients on POD0. The most common perceived barriers to early mobilisation from physiotherapists were the medical status of the patient $(53.6 \%)$, staffing resources $(53.6 \%)$, and surgeon preference $(29.6 \%)$. Pre-operative comorbidities measured using the American Society of Anaesthesiologist score have been associated with post-operative medical complications and increased LOS (Kimmel et al., 2011). As individuals undergoing TJA in the private sector have less comorbidities than those in the public sector (Naylor et al., 2019), this may have an impact on their medical status immediately post-operatively and thus their ability to mobilise safely on PODO.

In terms of post-operative orders or restrictions, variations still exist. For example, despite mounting evidence suggesting that removal of routine hip precautions after primary THA via posterior or anterolateral approach is safe (Dietz et al., 2019; Tetreault et al., 2020), 88\% of respondents reported either standard or modified hip precautions as routine for this population. For sites where THA via an anterior approach was completed $(62.4 \%)$, there was no consensus regarding use of routine precautions or restrictions. Where precautions were used, there was heterogeneity in the directions of movement restricted (Appendix $\mathrm{C}$ ). The risk of dislocation following primary THA is multifactorial and reportedly associated with surgery-, patient-, and implant-related factors (Kunutsor et al., 2019). Rather than using a 'one-size-fits-all' approach to precautions following THA, research suggests it may be useful to target modifiable patient factors pre-operatively and consider use of specific movement restrictions post-operatively based on intraoperative findings and the individual patient (Kunutsor et al., 2019).

\section{Study limitations}

Limitations include the high proportion of responses from two states (Victoria and New South Wales) and the need to pool data from smaller states in order to ensure they were deidentifiable. While it has been reported that paper-based surveys elicit greater response rates from allied health professionals than online surveys (Kidd et al., 2019), the time and monetary cost involved in distributing paper-based surveys was prohibitive for this project. An additional limitation is that while physiotherapists were asked to report how their institutions manage patients undergoing TJA, we did not collect objective measures against which to compare these assumptions.

\section{CONCLUSION}

Heterogeneity of care across the private and public healthcare sectors is described by physiotherapists for individuals undergoing elective TJA in Australia and New Zealand. Opportunities to research optimal management of individuals following TJA remain, particularly in regard to discharge destination, LOS, timing of first mobility, and criterion for discharge. Opportunity also exists to survey surgeons to document variances in surgeon preferences for pre- and postoperative care. Development of evidence-based clinical practice guidelines by an expert, multidisciplinary team may assist in reducing unwarranted variations and reducing the gap between evidence based and actual practice.

\section{KEY POINTS}

1. Heterogeneity in patient care following total joint arthroplasty (TJA) is reported by physiotherapists in public and private hospitals and across different regions in Australia and New Zealand.

2. Physiotherapists in private hospitals reported a longer length of stay, are more likely to mobilise their patients post-operatively on day 0 , and are more likely to offer a 7-day compared to 5-day physiotherapy service for patients following TJA.

3. Variation in post-operative management was reported in relation to precautions and early mobilisation.

4. Opportunity exists to develop clinical practice guidelines for the management of individuals receiving TJA to decrease unwarranted variations in care.

\section{DISCLOSURES}

No funding was received for this research. There are no conflicts of interest that may be perceived to interfere with or bias this study.

\section{PERMISSIONS}

Ethical approval was obtained from the Alfred Hospital Ethics Committee (project number 365/19). Participants indicated consent to participate by completion of the survey.

\section{ACKNOWLEDGMENTS}

The authors would like to thank the physiotherapists who provided their time to complete the survey.

\section{ADDRESS FOR CORRESPONDENCE}

Jessie Hart, Alfred Health, PO Box 315, Prahran, 3181, Melbourne, Victoria, Australia.

Email: j.hart2@alfred.org.au 


\section{REFERENCES}

Artz, N., Dixon, S., Wylde, V., Beswick, A., Blom, A., \& Gooberman-Hill, R. (2013). Physiotherapy provision following discharge after total hip and total knee replacement: A survey of current practice at high-volume NHS hospitals in England and Wales. Musculoskeletal Care, 11(1), 31-38. https://doi.org/10.1002/msc. 1027

Australian Commission on Safety and Quality in Health Care and Australian Institute of Health and Welfare. (2014). Exploring healthcare variation in Australia: Analyses resulting from an OECD study. https://www. safetyandquality.gov.au/publications-and-resources/resource-library/ exploring-healthcare-variation-australia-analyses-resulting-oecd-study

Australian Government Services Australia. (2020, April 15). Health care and Medicare. How you get affordable health care and access our services. https://www.servicesaustralia.gov.au/individuals/subjects/whats-coveredmedicare/health-care-and-medicare

Australian Institute of Health and Welfare. (2019a). Admitted patient care 2017-18: Australian hospital statistics (Health Services Series, Number 10). https://www.aihw.gov.au/getmedia/df0abd15-5dd8-4a56-94fac9ab68690e18/ainw-hse-225.pdf.aspx?inline=true

Australian Institute of Health and Welfare. (2019b, June 13). Disease expenditure in Australia. https://www.aihw.gov.au/reports/health-welfareexpenditure/disease-expenditure-australia/contents/summary

Australian Orthopaedic Association National Joint Replacement Registry (2018). Hip, knee \& shoulder arthroplasty: 2018 annual report. https:// aoanjrr.sahmri.com/documents/10180/576950/Hip\%2C\%20Knee\%20 $\% 26 \% 20$ Shoulder\%20Arthroplasty

Australian Orthopaedic Association National Joint Replacement Registry. (2020). Demographics of hip, knee and shoulder arthroplasty: 2020 annual report. https://aoanjrr.sahmri.com/documents/10180/689634/2020 +Demographics+Of+Hip+Knee+and+Shoulder+Arthroplasty

Churches, T., Naylor, J., \& Harris, I. A. (2019). Arthroplasty clinical outcomes registry national (ACORN) annual final report (2013-2018). Whitlam Orthopaedic Research Centre. http://www.acornregistry.org/images/ ACORN\%20Final\%20Report.pdf

Derrett, S., Bevin, T. H., Herbison, P., \& Paul, C. (2009). Access to elective surgery in New Zealand: Considering equity and the private and public mix. The International Journal of Health Planning and Management, 24(2), 147-160. https://doi.org/10.1002/hpm.978

Dietz, M. J., Klein, A. E., Lindsey, B. A., Duncan, S. T., Eicher, J. M., Gillig, J. D. Smith B. R., \& Steele, G. D. (2019). Posterior hip precautions do not impact early recovery in total hip arthroplasty: A multicenter, randomized controlled study. The Journal of Arthroplasty, 34(7, Suppl.), S221-S227.e1. https://doi.org/10.1016/j.arth.2019.02.057

Gaddis, G. M., \& Gaddis, M. L. (1990). Introduction to biostatistics: Part 5, statistical inference techniques for hypothesis testing with nonparametric data. Annals of Emergency Medicine 19(9), 1054-1059. https://doi. org/10.1016/S0196-0644(05)82571-5

Gwynne-Jones, D. P., Martin, G., \& Crane, C. (2017). Enhanced recovery after surgery for hip and knee replacements. Orthopaedic Nursing, 36(3) 203-210. https://doi.org/10.1097/NOR.0000000000000351

Haas, R., O'Brien, L., Bowles, K., \& Haines, T. (2018). Effectiveness of a weekend physiotherapy service on short-term outcomes following hip and knee joint replacement surgery: A quasi-experimental study. Clinical Rehabilitation, 32(11), 1493-1508. https://doi. org/10.1177/0269215518779647

Harris, P. A., Taylor, R., Minor, B. L., Elliott, V., Fernandez, M., O'Neal, L., McLeod, L., Delacqua, G., Delacqua, F., Kirby, J., \& Duda, S. N. (2019). The REDcap consortium: Building an international community of software platform partners. Journal of Biomedical Informatics, 95, 103208. https:// doi.org/10.1016/j.jbi.2019.103208

Harris, P. A., Taylor, R., Thielke, R., Payne, J., Gonzalez, N., \& Conde, J. G. (2009). Research electronic data capture (REDcap) —A metadata-driven methodology and workflow process for providing translational research informatics support. Journal of Biomedical Informatics, 42(2), 377-381. https://doi.org/10.1016/j.jbi.2008.08.010
Hooper, G., Lee, A. J.-J., Rothwell, A., \& Frampton, C. (2014). Current trends and projections in the utilisation rates of hip and knee replacement in New Zealand from 2001 to 2026. The New Zealand Medical Journal, 127(1401), 82-93.

Inacio, M. C. S., Graves, S. E., Pratt, N. L., Roughead, E. E., \& Nemes, S. (2017). Increase in total joint arthroplasty projected from 2014 to 2046 in Australia: A conservative local model with international implications. Clinical Orthopaedics and Related Research, 475(8), 2130-2137. https:// doi.org/10.1007/s11999-017-5377-7

Jones, C. A., Martin, R. S., Westby, M. D., \& Beaupre, L. A. (2016) Total joint arthroplasty: Practice variation of physiotherapy across the continuum of care in Alberta. BMC Health Services Research, 16, 627. https://doi. org/10.1186/s12913-016-1873-9

Kidd, J. C., Colley, S., \& Dennis, S. (2019). Surveying allied health professionals within a public health service: What works best, paper or online? Evaluation \& the Health Professions. Advance online publication. https://doi.org/10.1177/0163278719870568

Kimmel, L. A., Oldmeadow, L. B., Sage, C., Liew, S. M., \& Holland, A. E. (2011). A designated three day elective orthopaedic surgery unit: First year's results for hip and knee replacement patients. International Journal of Orthopaedic and Trauma Nursing, 15(1), 29-34. https://doi. org/10.1016/j.ijotn.2010.07.001

Kunutsor, S. K., Barrett, M. C., Beswick, A. D., Judge, A., Blom, A. W., Wylde, V., \& Whitehouse M. R. (2019). Risk factors for dislocation after primary total hip replacement: A systematic review and meta-analysis of 125 studies involving approximately five million hip replacements. The Lancet Rheumatology, 1(2), e111-e121. https://doi.org/10.1016/S26659913(19)30045-1

Lao, C., Lees, D., Patel, S., White, D., \& Lawrenson, R. (2010). Geographical and ethnic differences of osteoarthritis-associated hip and knee replacement surgeries in New Zealand: A population based crosssectional study. BMJ Open, 9(9), e032993. https://doi.org/10.1136/ bmjopen-2019-032993

London, D. A., Vilensky, S., O'Rourke, C., Schill, M., Woicehovich, L., \& Froimson, M. I. (2016). Discharge disposition after joint replacement and the potential for cost savings: Effect of hospital policies and surgeons. The Journal of Arthroplasty, 31(4), 743-748. https://doi.org/10.1016/j. arth.2015.10.014

Meneghini, R., Gibson, W., Halsey, D., Padgett, D., Berend, K., \& Della Valle, C.J. (2018). The American Association of Hip and Knee Surgeons, Hip Society, and American Academy of Orthopaedic Surgeons position statement on oupatient joint replacement. The Journal of Arthroplasty, 33(12), 3599-3601. https://doi.org/10.1016/j.arth.2018.10.029

Naylor, J., Harmer, A., Fransen, M., Crosbie, J., \& Innes, L. (2006). Status of physiotherapy rehabilitation after total knee replacement in Australia. Physiotherapy Research International, 11(1), 35-47. https://doi. org/10.1002/pri.40

Naylor, J. M., Hart, A., Harris, I. A., \& Lewin, A. M. (2019). Variation in rehabilitation setting after uncomplicated total knee or hip arthroplasty: A call for evidence-based guidelines. BMC Musculoskeletal Disorders, 20 214. https://doi.org/10.1186/s12891-019-2570-8

Pengas, I. P., Khan, W. S., Bennett, C. A., \& Rankin K. S. (2015). Impact of weekend physiotherapy service on the cost effectiveness of elective orthopaedic hip and knee arthroplasty. The Open Orthopaedics Journal, 9(Suppl. 2), 515-519. https://doi.org/10.2174/1874325001509010515

Proudfoot, S., Bennett, B., Duff, S., \& Palmer, J. (2017). Implementation and effects of enhanced recovery after surgery for hip and knee replacements and fractured neck of femur in New Zealand orthopaedic services. New Zealand Medical Journal, 130(1455), 77-90

Royal Australasian College of Surgeons. (2018). Rehabilitation pathways following hip and knee arthroplasty. https://www.surgeons.org/-/media/ Project/RACS/surgeons-org/files/reports-guidelines-publications/surgicalvariance-reports/2018-01-29 mbp arthroplasty final.pdf?rev=cad69a22 5 fee486eadd75779bf7b8425\&hash=8C C9E285C9E886440BCBA25A1A 86FOED 
Schilling, C., Keating, C., Barker, A., Wilson, S. F., \& Petrie, D. (2018). Predictors of inpatient rehabilitation after total knee replacement: An analysis of private hospital claims data. Medical Journal of Australia, 209(5), 222-227. https://doi.org/10.5694/mja17.01231

Sconza, C., Respizzi, S., Grappiolo, G., \& Monticone, M. (2019). The risk assessment and prediction tool (RAPT) after hip and knee replacement: A systematic review. Joints, 7(2), 41-45. https://doi. org/10.1055/s-0039-1693459

Snell, D. L., Sinnott Jerram, K. A., Dunn, J. A., Hsieh, C. J., DeJong, G., \& Hooper, G. J. (2020). Use of rehabilitation after hip and knee replacement in New Zealand: A national survey. The New Zealand Medical Journal, 133(1510), 45-55
Tayrose, G., Newman, D., Slover, J., Jaffe, F., Hunter, T., \& Bosco, J. (2013). Rapid mobilization decreases length-of-stay in joint replacement patients. Bulletin of the Hospital for Joint Disease, 71(3), 222-226.

Tetreault, M. W., Akram, F., Li, J., Nam, D., Gerlinger, T. L., Della Valle, C. J., \& Levine, B. R. (2020). Are postoperative hip precautions necessary after primary total hip arthroplasty using a posterior approach? Preliminary results of a prospective randomized trial. The Journal of Arthroplasty, 35(6, Suppl.), S246-S51. https://doi.org/10.1016/j.arth.2020.02.019

The New Zealand Joint Registry. (2019). Twenty year report: January 1999 to December 2018. https://nzoa.org.nz/sites/default/files/DH8328_ NZJR_2019_Report_v4_7Nov19.pdf 


\section{Appendix A}

DISCHARGE CRITERIA FOR PATIENTS WITH TOTAL HIP ARTHROPLASTY $(N=125)$

\begin{tabular}{|c|c|c|c|c|c|c|c|}
\hline \multirow{2}{*}{ Criteria } & \multicolumn{2}{|c|}{ Total } & \multicolumn{2}{|c|}{ Private hospital } & \multicolumn{2}{|c|}{ Public hospital } & \multirow[t]{2}{*}{$p$} \\
\hline & $n$ & $\%$ & $n$ & $\%$ & $n$ & $\%$ & \\
\hline \multicolumn{8}{|c|}{ Range of movement goal } \\
\hline Yes & 6 & 4.8 & 2 & 4.5 & 4 & 4.9 & \multirow{2}{*}{1.000} \\
\hline No & 119 & 95.2 & 42 & 95.5 & 77 & 95.1 & \\
\hline \multicolumn{8}{|c|}{ No quadriceps lag } \\
\hline Yes & 6 & 4.8 & 3 & 6.8 & 3 & 3.7 & \multirow{2}{*}{0.664} \\
\hline No & 119 & 95.2 & 41 & 93.2 & 78 & 96.3 & \\
\hline \multicolumn{8}{|c|}{ Independent with home exercise programme } \\
\hline Yes & 50 & 40.0 & 23 & 52.3 & 27 & 33.3 & \multirow{2}{*}{0.039} \\
\hline No & 75 & 60.0 & 21 & 47.7 & 54 & 66.7 & \\
\hline \multicolumn{8}{|c|}{ Independent with personal activities of daily living } \\
\hline Yes & 72 & 57.6 & 25 & 56.8 & 47 & 58.0 & \multirow{2}{*}{0.896} \\
\hline No & 53 & 42.4 & 19 & 43.2 & 34 & 42.0 & \\
\hline \multicolumn{8}{|c|}{ Independent with mobility } \\
\hline Yes & 124 & 99.2 & 43 & 97.7 & 81 & 100 & \multirow{2}{*}{0.352} \\
\hline No & 1 & 0.8 & 1 & 2.3 & 0 & 0 & \\
\hline \multicolumn{8}{|c|}{ Independent with transfers } \\
\hline Yes & 116 & 92.8 & 41 & 93.2 & 75 & 96.2 & \multirow[t]{2}{*}{1.000} \\
\hline No & 9 & 7.2 & 3 & 6.8 & 6 & 7.3 & \\
\hline
\end{tabular}

\section{Appendix B}

DISCHARGE CRITERIA FOR PATIENTS WITH TOTAL KNEE ARTHROPLASTY $(N=125)$

\begin{tabular}{|c|c|c|c|c|c|c|c|}
\hline \multirow{2}{*}{ Criteria } & \multicolumn{2}{|c|}{ Total } & \multicolumn{2}{|c|}{ Private hospital } & \multicolumn{2}{|c|}{ Public hospital } & \multirow{2}{*}{$p$} \\
\hline & $n$ & $\%$ & $n$ & $\%$ & $n$ & $\%$ & \\
\hline \multicolumn{8}{|c|}{ Range of movement goal } \\
\hline Yes & 77 & 61.6 & 22 & 50.0 & 55 & 67.9 & \multirow{2}{*}{0.049} \\
\hline No & 48 & 38.4 & 22 & 50.0 & 26 & 32.1 & \\
\hline \multicolumn{8}{|c|}{ No quadriceps lag } \\
\hline Yes & 18 & 14.4 & 6 & 13.6 & 12 & 14.8 & \multirow{2}{*}{0.858} \\
\hline No & 107 & 85.6 & 38 & 86.4 & 69 & 85.2 & \\
\hline \multicolumn{8}{|c|}{ Independent with home exercise programme } \\
\hline Yes & 55 & 44.0 & 25 & 56.8 & 30 & 37.0 & \multirow{2}{*}{0.033} \\
\hline No & 70 & 56.0 & 19 & 43.2 & 51 & 63.0 & \\
\hline \multicolumn{8}{|c|}{ Independent with personal activities of daily living } \\
\hline Yes & 72 & 57.6 & 25 & 56.8 & 47 & 58.0 & \multirow{2}{*}{0.896} \\
\hline No & 53 & 42.4 & 19 & 43.2 & 34 & 42.0 & \\
\hline \multicolumn{8}{|c|}{ Independent with mobility } \\
\hline Yes & 124 & 99.2 & 43 & 97.7 & 81 & 100 & \multirow{2}{*}{0.352} \\
\hline No & 1 & 0.8 & 1 & 2.3 & 0 & 0 & \\
\hline \multicolumn{8}{|c|}{ Independent with transfers } \\
\hline Yes & 118 & 94.4 & 42 & 95.5 & 76 & 93.8 & \multirow[t]{2}{*}{1.000} \\
\hline No & 7 & 5.6 & 2 & 4.5 & 5 & 6.2 & \\
\hline
\end{tabular}


Appendix C

DIRECTION OF RESTRICTIONS FOR HOSPITALS WITH PRECAUTIONS FOLLOWING ANTERIOR APPROACH $(N=55)$

\begin{tabular}{lrr}
\hline Direction & $n$ & $\%^{\mathrm{a}}$ \\
\hline Flexion & 7 & 12.7 \\
Extension & 42 & 76.4 \\
Abduction & 8 & 14.5 \\
Adduction & 11 & 20.0 \\
Internal rotation & 6 & 10.9 \\
External rotation & 3 & 5.1 \\
Straight leg raise & 5 & 14.5 \\
Pivot/twist on operated leg & 5 & \\
\hline
\end{tabular}

a Percentage $\neq 100$ as some sites reported multiple directions of movement restriction. 